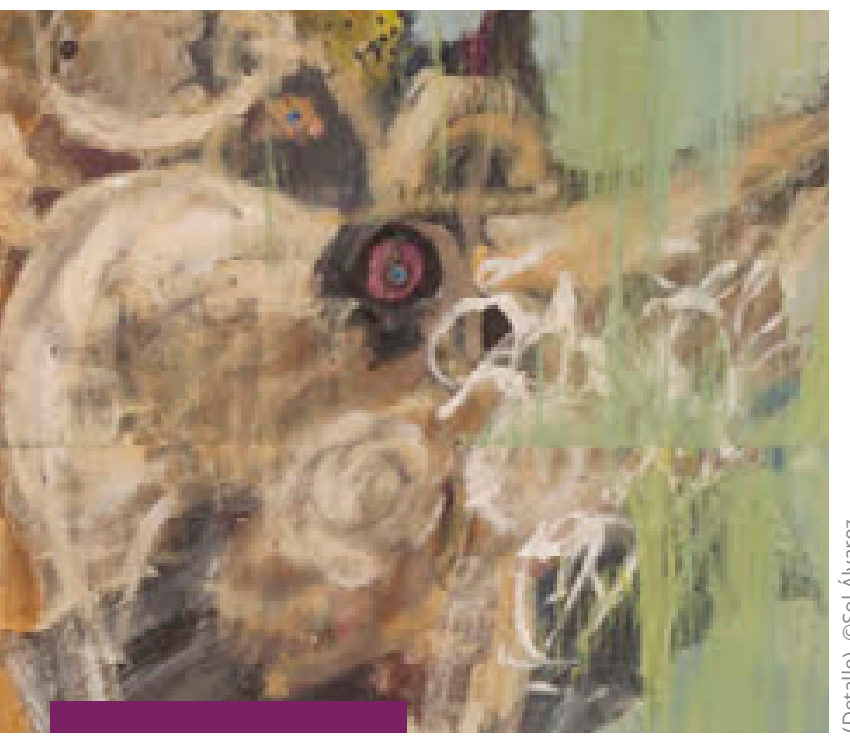

FIGURAS REVISTA ACADÉMICA DE INVESTIGACIÓN

ISSN 2683-2917

Vol. 2, núm. 2, marzo-junio 2021

https://doi.org/10.22201/fesa.figuras.2021.2.2

Esta obra está bajo una licencia

Creative Commons Atribución-NoComercial-

Compartirlgual 4.0 Internacional

\section{Sol Álvarez, el arte como identidad}

\section{Sol Álvarez, Art as an Identity}

https://doi.org/10.22201/fesa.figuras.2021.2.2.155

\section{José Ángel Leyva}

Universidad Autónoma de la Ciudad de México

La artista plástica Sol Álvarez desarrolla un discurso estético fundado en su formación teórica en los terrenos del arte, en su ejercicio crítico e investigación en la historia del arte y los artistas, y lo asume bajo el principio de la mayordomía, es decir, en el legado de un don del cual es responsable y que reconoce en sí el magisterio de quienes le han mostrado las herramientas y los recursos de la creación. Mayordomía como disciplina y como rebelión.
Desde cualquier ángulo el arte es un medio y un fin para la revelación, a veces brota en las proximidades del inconsciente, o no demasiado, a menudo emerge como lenguaje que se estructura para re-conocer espacios que habitan al sujeto y que éste suele visitar, incluso morar. La famosa frase de Gustave Flaubert "Madame Bovary, c'est moi", capaz de retirar los velos de la sospecha acerca del lugar que ocupan los personajes en el mundo del autor, de su responsabilidad y sus vínculos - semejante relación habrán de tener los lectores que encuentren esa energía estética en la obra del novelista. No es un caso de travestismo, sino la fuerza que anima al sujeto de la ficción hasta imponerlo en la realidad del individuo, por la creación y recreación que cada uno es capaz de hacer. En Sol Álvarez dicho lenguaje aparece en su juventud madura, brota en principio como un discurso argumental para, casi sin proponérselo, emerger como un río subterráneo. No posee, es cierto, los instrumentos de la academia, las técnicas de una cocina ortodoxa, pero tiene en su haber el fundamento de la teoría, el conocimiento de la historia, la información de escuelas y de autores, el saber de la vista y la cultura de libros y museos que constituyen un rico bagaje. Sol Álvarez se da luz a sí misma en esta primera acción plástica gestada en su biografía familiar, en el rumor de la infancia y en la marcha de los tiempos. Una obra como trasunto de la identidad y la memoria.

\section{¿De dónde saco que soy artista?}

Sol expresa o manifiesta su relación de respeto y admiración hacia los grandes maestros y las obras supremas desde lo que ella denomina la mayordomía. Una forma, tal vez, de justificar su aparición tardía en el arte, pero también un modo de colocarse en la posición de quien está abierto al aprendizaje con avidez y apego a la otra experiencia, al otro conocimiento. La mayordomía de quien recibe un don y una responsabilidad en las manos para su administración 
y resguardo. No obstante, lo interpreta también como un recurso de posesión y pertenencia de un bien que no es la obediencia, sino justamente lo contrario: la insurrección, la inconformidad como principio rector del acto creativo.

Conmueve - no sólo- y reafirma su vocación estética la capacidad de interrogarse con pudor si es en verdad una artista, si lo que hace posee tal categoría. La mayoría de los auténticos creadores se cuestionan no sólo en sus inicios sino toda la vida si lo son, sobre todo cuando deciden acometer un objetivo más alto, cuando atienden a un deseo de naturaleza temeraria y el pudor y la timidez los obliga a reflexionar ante el temor del fracaso o sobre la viabilidad del arrojo. Pero cuando el deseo vence al miedo y a la inseguridad sólo queda el camino, la determinación, la entrega. El deseo se convierte en necesidad y la necesidad en virtud, lo demás lo pone el talento, la sensibilidad, el saber y la magia para convertir lo banal en suceso extraordinario. Si para el poeta el lenguaje es su patria, para el artista también lo es. Es allí donde encuentra el territorio de sus primeros y de sus últimos días, donde comienza a ser y hacer con los otros su individualidad.

La memoria y el aprendizaje corren unidos en la etapa formativa y resolutiva de la artista, quien halla motivos para pintar sobre las huellas de sus maestros y guías, para ensamblar y pegar materiales reciclables sobre los rastros de la historia, en las cicatrices de utopías cubiertas aún de costras y preguntas, de migraciones forzadas por la sobrevivencia y el odio. Sol asume la encomienda de un pasado inmediato en su conciencia, más como anecdotario que como vivencia propia. La Guerra Civil Española condenó a su

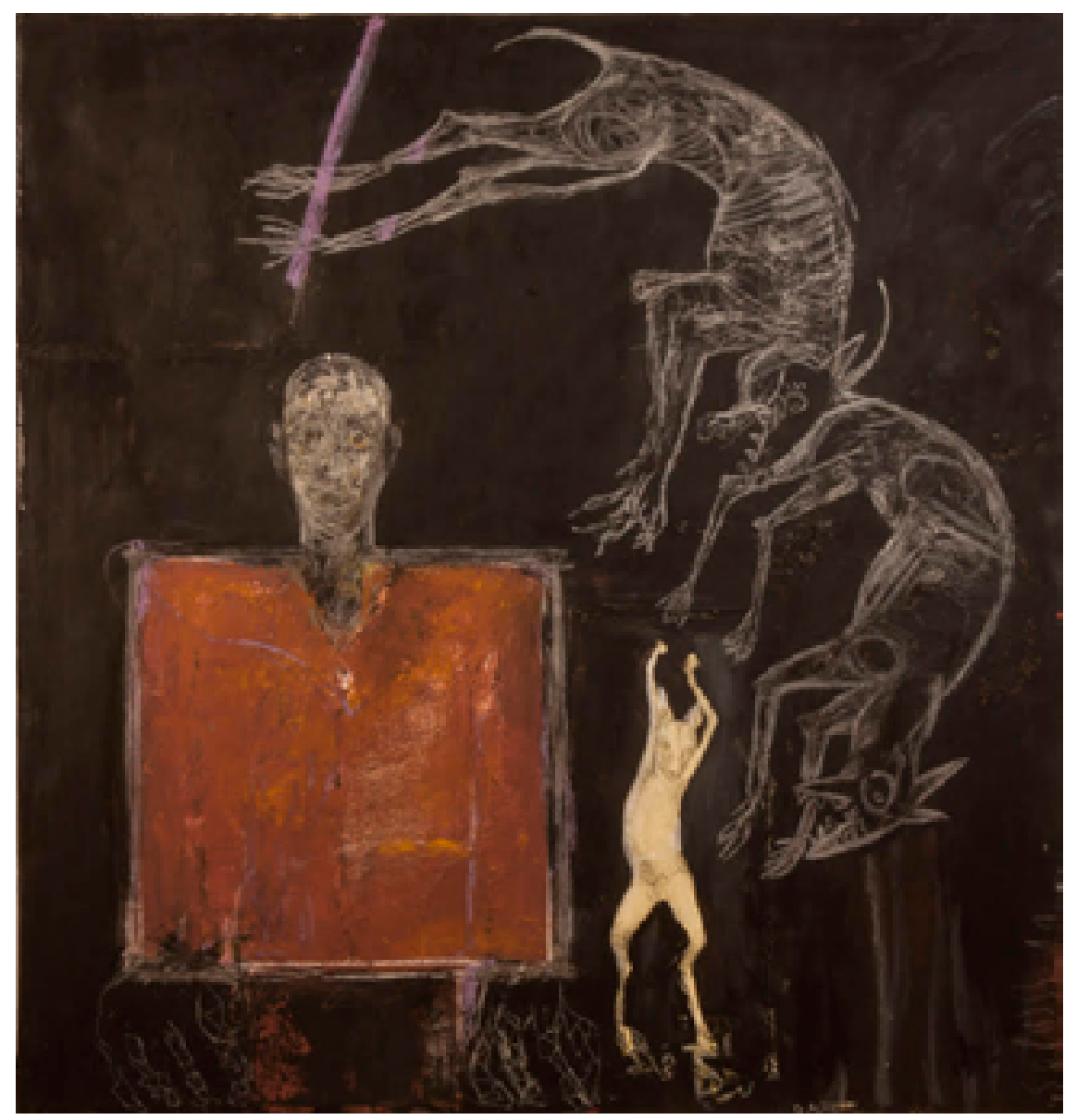

(c)Sol Álvarez. 
abuelo paterno, republicano y comunista, al exilio en México, luego el régimen franquista lo recluyó durante más de 20 años cuando él volvió a su patria para continuar luchando por la causa.

El desafío de la artista es disolver la anécdota, transformar el relato en una expresión estética que signifique, sintetice ideas, hechos, abra cauce a los símbolos. Sol deja correr en su poética dos cursos temporales, dos vertientes líricas que se entreveran y distancian: la historia política del siglo xx y la historia del arte de la misma centuria y más atrás. De allí quizás su nacimiento entre ruinas, despojos de una civilización que se vuelca hacia nuevas guerras y formas de dominio, de viejos e inéditos fenómenos, de actualidades ancestrales reescritas como palimpsestos en el estupor y en la ignorancia. Una pedacería que es también material de su propuesta artística, desechos y reciclables al servicio de un discurso. El artista se revela y se rebela también en ese revoltijo de emociones y preguntas, en ese desconcierto de la mente y de los sentidos, en la claridad del agua que brota por la piedra del no saber sabiendo de los místicos y el arte. Estamos ante una certidumbre, Sol quiere ser artista, y quiere serlo porque lo es. Su obra es el testimonio de una larga reflexión para re-conocerse y ser, ya no en el extravío, sino en la lucidez.

\section{Lo bello y lo significativo}

Además de una catarsis psicológica, hay una liberación sensible, una toma de posición, o de posesión si se quiere, ante la belleza, ante el equilibrio de las formas para soltar amarras en la libertad de los significados, aun cuando los cánones de lo bello se ven cuestionados. Con el sedimento de imágenes de un discurso narrativo, Sol formula un diálogo entre el ejercicio conceptual y el simbolismo expresivo (que no expresionismo simbólico), vasos comunicantes entre la escritura reflexiva y el irracionalismo estético. Expresa la violencia de una guerra fratricida o la descomposición cultural de una sociedad dominada por la crueldad y la indiferencia, el exterminio como práctica divisoria del planeta, guerras multinacionales o mundiales, pauperización, hambre y olvido de enormes masas humanas. Todo ello tiene sitio en ese sistema de símbolos propuesto por la artista. La de Sol no es una acción a la manera del valenciano Josep Renaud, que hizo del fotomontaje y el collage un arte político, un medio para expresar su visión de la sociedad de consumo, del capitalismo salvaje, de la crítica al fascismo, fuertemente influenciado por las vanguardias europeas y el constructivismo ruso, que lo ponían a salvo de un resultado propagandístico. La violencia y la intolerancia hacia sí mismo del animal político o religioso manifiesto en títulos como " $\mathrm{Fu}$ silar al diablo", "Casquillos por doquier", "Falange contra mundo obrero", "Falange fusila a Calígula y Nerón", de la serie La perla y el charal, o de la serie Mundo: "Derrame de petróleo", "Reconocimiento", y "Perros", cuadro con el cual Sol refrenda gratitud y disposición al magisterio de sus colegas y amigos, en este caso a su tutor y compañero Juan Sánchez Juárez, con quien comparte el crédito de la obra en una suerte de acoplamiento y reelaboración, de diálogo y complicidad sobre una pintura del segundo, de la que sólo queda la figura bien definida de un perro. Sucede también en su serie Pintores, donde ese intercambio de miradas perfila efectos distintos en el espectador que deviene autor. Sol nos ofrece la versión de la memoria, la inconformidad afectiva y racional de obras y maestros que no por admirados pertenecen al mundo de la contemplación pasiva -Théodore Géricault, Goya, Dalí, Buñuel, Tarkovsky, por mencionar algunos artistas visuales, son motivo de interpelación y homenajes a la vez.

\section{Los símbolos y el tiempo}

No se podría hablar de una paleta en el caso de Sol, aunque la haya, porque en realidad existe un impulso 


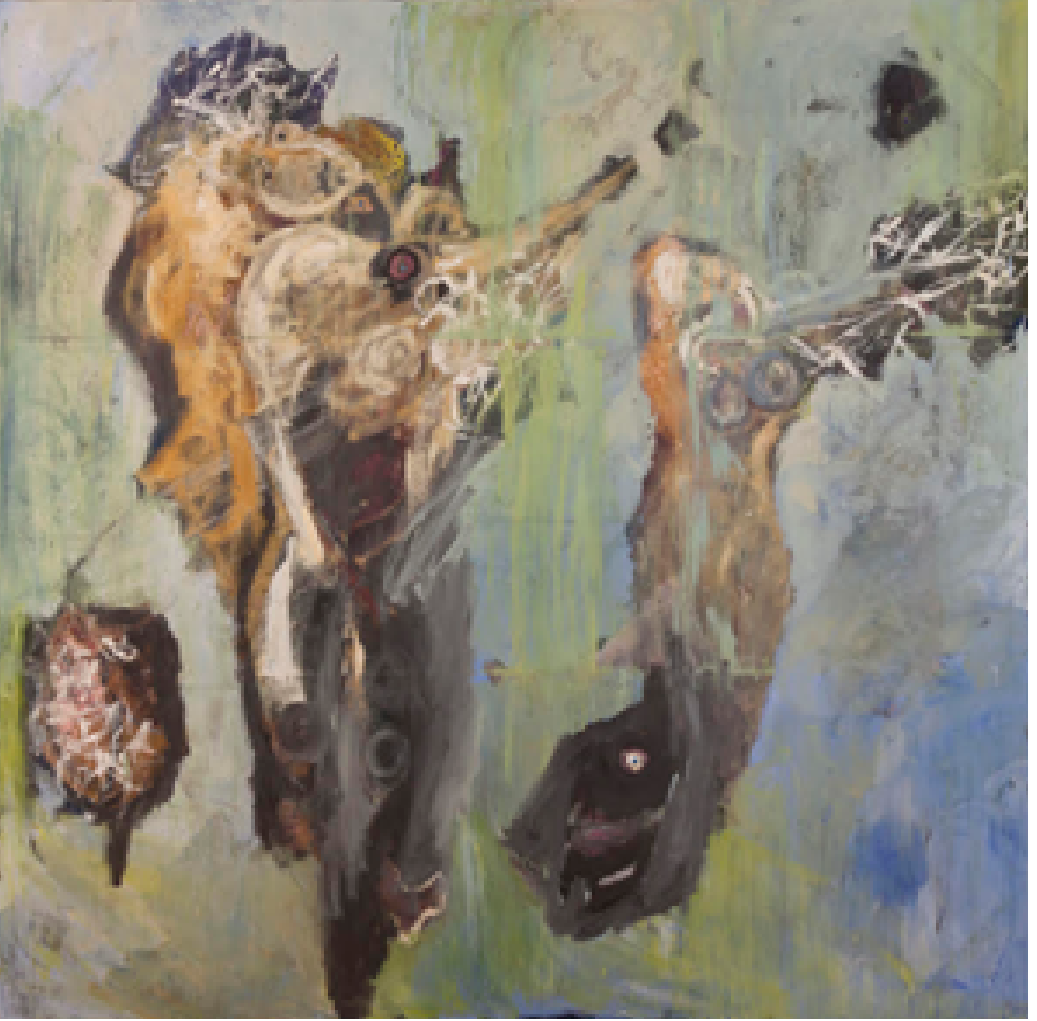

C)Sol Álvarez.

de cambio constante en esta fase de su trayectoria como artista, una búsqueda incesante y hasta frenética en su obra. Esta necesidad de muda constante podría ser el signo de identidad de su trabajo -o por el contrario, el riesgo de no consolidar una "voz personal"-, de naturaleza interrogante, de rechazo al estilo o al asentamiento del lenguaje propio que se interna y emerge en el fondo de una galería de opciones y afinidades, de posibilidades técnicas. Limitaciones y alcances que irán determinando el lenguaje definitivo de quien posee, sin lugar a duda, un rico surtidor conceptual e informativo.

La formación académica de Sol y sus antecedentes profesionales representan un fuerte soporte teórico a su horizonte creativo. Licenciada en Historia por la Facultad de Filosofía y Letras y maestra en Semiótica aplicada a la imagen, ha publicado dos libros: Arte y Centralismo y Procesos curatoriales. La obra de Silvia Barbescu, y ha concluido el tercero: Política cultural en Oaxaca y Francisco Toledo. Su trabajo en el Centro
Nacional de Investigación, Documentación e Información de Artes Plásticas (Cenidiap) y en el Centro Nacional de las Artes como investigadora, respalda con holgura esta búsqueda de lenguaje propio en las artes plásticas. No es desdeñable su experiencia como editora de libros en su obra artística, pues en todo discurso la noción sintáctica es fundamental, la lectura atenta del texto y sus contextos, la pertinencia de una propuesta en el marco de sus antecedentes y antecesores, de su actualidad, la relación misma de sus partes con el todo y el todo con las partes que la constituyen, pero más que nada en la identificación de sus signos, en la visibilidad de sus imágenes, en la legibilidad de su discurso. Más allá de una valoración estética, no puede negarse justamente esa virtud en la obra de Sol Álvarez, claridad discursiva, sustentación de motivos desde que ella misma se declarara artista plástica autodidacta, en 2011.

Los símbolos y el tiempo, y los símbolos a través del tiempo forman parte de la elaboración discursiva de esta obra, pues abre su registro de presencias emblemáticas, icónicas, desde los Desastres de la guerra y Los Caprichos de Goya hasta el arte bizantino, donde evidentemente el dibujo es apenas una insinuación entre diversos recursos de expresión visual que pretenden otorgarle gravedad, texturas y volumen a los cuadros. Lo político es el sustrato de este primer peldaño tan plural en sus técnicas como en sus asuntos, que pueden ir desde el salto del mono al hombre, como en el cuadro titulado "Engels", hasta "Retrato de mis padres" I y II, que nos sugiere La sagrada familia o crítica de la crítica de Carlos Marx y Federico Engels. La propia autora pretendía titularlos retretes en lugar de retratos; lo más evidente en el II es el símbolo fálico de esta institución social y la presencia de los libros como mecanismo de transmisión del conocimiento y de sus interrogantes. La crudeza es otro de los distintivos del discurso estético de Sol. No obstante, se aleja suficiente de la obviedad para, sin perder su significado "ideológico", motivar otro tipo de interpretaciones en las que no cabe el panfleto o la consigna, el 
mensaje o la moraleja. Imágenes en las que la figura pierde realismo y las proporciones humanas juegan en las manos de un niño o en una pintura rupestre, donde son más símbolos, manchas, borrones, ralladuras, esgrafiados, chorretones que definen fondos y atmósferas abstractas.

El humor es uno de sus ingredientes de cohesión. Entre la ingenuidad y el sarcasmo, Sol recurre a la pregunta más que a la sentencia, la confrontación se da primero con ella misma, luego nos coloca a nosotros, espectadores, ante los significados de una belleza sin atributos, gobernada por el crimen, por una moral de conveniencia. Sol no hace caricatura, pero caricaturiza la historia y el arte, a la sociedad y a la civilización. Ironiza y desolemniza.

El collage es una técnica muy socorrida en su trabajo. Echa mano de cuanto halla a su paso para poblar de significados cuadros de gran formato y cuyo soporte es casi siempre madera, láminas u otros materiales sólidos que pueden cuajarse de desechos no precisamente ligeros. Los hay también leves, como fotografías, periódicos o documentos sobre los cuales monta otros papeles o dibuja y mancha como lo ha hecho con gran fortuna Pierre Alechinsky, situado también en alguna de las coordenadas por donde Sol hace sus búsquedas.

La gravedad es, en todos los sentidos, y aún con el humor, un factor dominante. Sorprende la presencia de piedras y artefactos de proporciones considerables en sus creaciones, desechos industriales o de construcción que vienen a darle no sólo peso, sino un carácter notablemente grave a la obra. Esa lucha interna entre la pesadez y la ligereza se desplaza hacia lo abstracto, se carga y se descarga de elementos, se desvanece y aparece con manifiesta curiosidad en la creación de atmósferas y fondos, se revuelve contra sí misma, se indaga ya en los dominios del volumen y de los objetos escultóricos. La identidad tiene cara de carta de naturalización, Sol está inventando o definiendo su lengua.

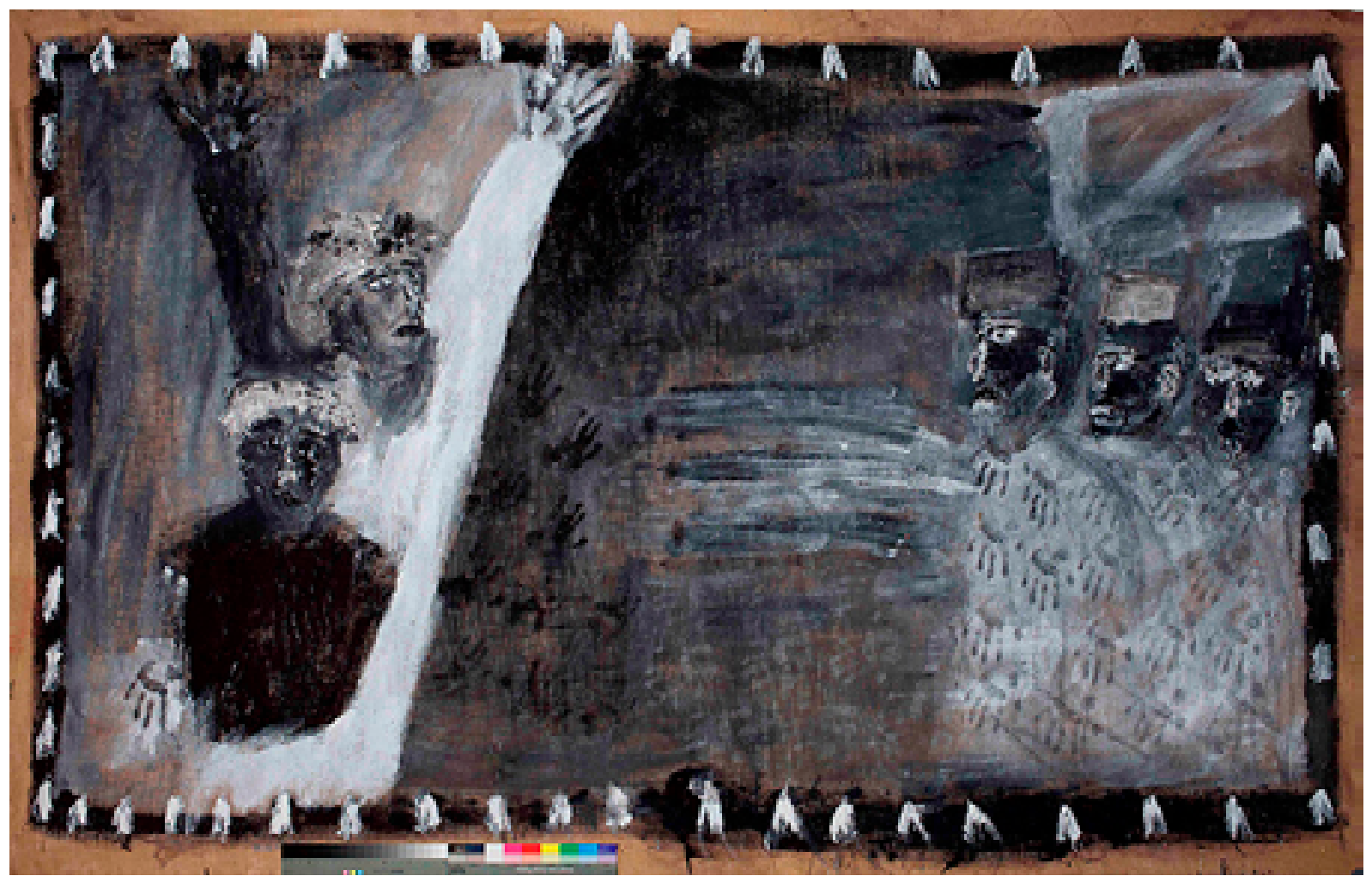

(c)Sol Álvarez. 